\title{
IL-17 and Its Receptor System: a New Target for Psoriatic Arthritis
}

\author{
Smriti K. Raychaudhuri, $M D^{1,2}$ \\ Siba P. Raychaudhuri, $M D^{1,2,3, *}$
}

\author{
Address \\ ${ }^{1}$ VA Medical Center Sacramento, Internal Medicine/Rheumatology, Mather, CA, USA \\ ${ }^{2}$ School of Medicine, University of California Davis, Mather, CA, USA \\ *,3Division of Rheumatology, Allergy \& Clinical Immunology, School of Medicine, \\ University of California Davis, 10535 Hospital Way, Bldg \# 650 Research Service, \\ Mather, CA 95655, USA \\ Email: sraychaudhuri@ucdavis.edu
}

Published online: 27 March 2015

(C) Springer International Publishing AG 2015

This article is part of the Topical Collection on Spondyloarthritis and Psoriatic

Arthritis

Siba P. Raychaudhuri is Chief of Rheumatology, VA Medical Center Sacramento

Keywords $\mathrm{T}_{\mathrm{h}} 17 \cdot \mathrm{IL}-17 \cdot$ Psoriasis P Psoriatic arthritis

\section{Opinion statement}

$T_{h} 17$ cells are one subset of $T$ cells, which produce IL-17, a pro-inflammatory cytokine. A regulatory role of $T_{h} 17$ cells has been proposed in several autoimmune diseases including psoriasis, psoriatic arthritis, rheumatoid arthritis, inflammatory bowel disease, systemic lupus enthematosus, and multiple sclerosis. Psoriatic disease is an autoimmune disease which mainly involves skin and joints. Until recently, psoriasis and psoriatic arthritis were thought to be Th1mediated disease, but after the discovery of IL-17 and IL-17, knockout animal studies as well as human experimental data indicate the crucial role of the $T_{h} 17$ cells in the pathogenesis of psoriatic disease. Human studies have shown the presence of $T_{h} 17$ cells in the psoriatic plaques in excess. Moreover, our research group not only have found abundance of $\mathrm{CD} 4^{+} \mathrm{IL}-17^{+} \mathrm{T}$ cells, mainly the memory phenotype ( $\left.C D 4 R 0^{+} C D 45 \mathrm{RA}^{-} \mathrm{CD} 11 \mathrm{a}^{+}\right)$in the synovial fluid, but also have shown the existence of functional IL-17 receptor in synovial fibroblast of psoriatic arthritis patients. In this review article, we have discussed the contributing role of the IL-23/IL-17 axis in psoriatic arthritis (PSA) and the prospective of IL-17 targeted therapies in PsA.

\section{Introduction}

Psoriasis and psoriatic arthritis (PsA), often termed as share certain similar pathological events and clinical "psoriatic disease," are autoimmune diseases which features [1-3]. PsA is a heterogeneous disease 
characterized by involvement of the skin, nails, peripheral and axial joints, and entheses. PsA is a seronegative autoimmune inflammatory joint disease that develops in approximately $25 \%$ of the psoriasis patients usually within 10 years of start of skin manifestations. In $\sim 10 \%$ of patients, the arthritis appears before the inception of skin disease [4-6]. Apart from arthritis, psoriasis is also associated with multiple physical and psychological comorbidities like hypertension, dyslipidemia, diabetes mellitus, obesity, nonalcoholic fatty liver disease, metabolic syndrome, anxiety, depression, and suicidal tendency [3, 7-13]. The variety of affected organ systems and the associated co-morbidities make the clinical diagnosis and management of PsA challenging.

Although considerable progress has been made in deciphering the pathogenesis of psoriatic disease, the exact cause still remains a mystery. Psoriatic disease is a multifactorial disease involving a complex interaction of genetic, immunologic, and environmental factors that modify the function of lymphocytes, neutrophil epidermal keratinocytes, synovial cells (fibroblast-like synovial cells (FLS)), and osteoclasts through important cytokines/chemokines $[2,4,7]$. A variety of genetic, immunologic, and environmental factors have been suggested to contribute to PsA pathogenesis [3, 4, 14-16]. Single nucleotide polymorphisms in IL23A, IL23R, as well as TRAF3IP2 (Act1), a downstream target of the IL17 receptor (IL-17R), confer susceptibility to PsA, implying a central role of the IL-23/IL-17 axis in PsA disease pathogenesis [17-19]. Considering the strong association of IL-17 and psoriatic disease, IL-17 targeted therapy for PsA has been developed and has shown promises in preclinical and clinical trials. In this review article, we have discussed the contribution of the IL-23/IL-17 axis in PsA and summarized the therapeutic efficacy and safety profile of different anti IL-17 therapeutic agents.

\section{Immunopathogenesis of psoriatic disease}

The inflammation associated with psoriasis is a sequel of multiple pathological events. The disease is primarily characterized by hyperplasia of epidermal keratinocytes, angiogenesis, and infiltration of immune cells in the affected skin. The immunopathogenesis of psoriatic disease is complex and still evolving. In this complex milieu, pathogenic $T$ cell subpopulations $\left(T_{h} 1, T_{h} 17, T_{h} 22\right)$ and their signature cytokines (IFN- $\gamma$, IL-1 $\beta$, IL-6, TNF- $\alpha$, IL-17, IL-22), chemokines, adhesion molecules, growth factors like nerve growth factor (NGF), and neuropeptides act in an integrated way through their corresponding receptors to evolve pathognomonic features of psoriasis and psoriatic arthritis $[3,4,16-21]$. Cytokines are the primary products of immune activation. Various cytokines play a detrimental role in the psoriasis pathogenesis; however, understanding of their role in the disease is still limited. The role of innate and adaptive immune responses is now well established in its pathogenesis. Psoriatic disease is strongly believed as a T cell-mediated autoimmune disease of the skin and joints based upon the following observations: (i) $\mathrm{CD} 4^{+} \mathrm{T}$ cell targeted immunotherapy clears active plaques of psoriasis [22]; (ii) transplanted nonlesional psoriatic skin converts to a psoriatic plaque subsequent to intradermal administration of T cells activated with an antigen cocktail in SCID mice [23]; (iii) blocking of the T cell co-stimulatory molecule improves psoriasis in the SCID mouse-psoriasis xenograft model [24]; (iv) $\mathrm{T}_{\mathrm{h}} 17$ celldriven cytokines contribute to the pannus formation, osteoclast activation, and new bone formation in PsA [17-19, 25-27].

Recent evidence indicates that interleukin 23 (IL-23) may be a master cytokine in psoriasis. IL-23 activates the $\mathrm{T}_{\mathrm{h}} 17$ cells to produce $\mathrm{T}_{\mathrm{h}} 17$ cytokines such as IL-17 and IL-22. $\mathrm{T}_{\mathrm{h}} 17$ cell-derived cytokines will have more downstream effects such as epidermal thickening, synovial inflammation, angiogenesis, and 
cell trafficking [25-28] (Fig. 1). Findings suggest that these cytokines are interwoven. We will illustrate the role of various cytokines in the pathogenesis of psoriatic disease and the apparent inflammatory interplay between the cytokines, epithelial tissues, endothelial cells, osteoclasts, and osteoblasts.

\section{IL-17 and its receptor system}

Following the discovery of the IL-17 encoding gene in a rodent T cell library in the early 1990s, its human homologue with a cytokine-like activity was identified and labeled as IL-17 [29]. So far, IL-17A (commonly termed as IL-17) followed by IL-17F has been extensively studied amongst the six IL-17 family cytokines (IL-17A to IL-17F) [30]. IL-17A and IL-17F have $55 \%$ amino acid resemblance and exist as homodimers sharing structural similarity having a disulfide bond and a cystine knot fold and sometimes as heterodimers IL-17A/F with inflammatory potential [31-33]. IL-17 receptor (IL-17R) complex is also multimeric analogous to IL-17. The earliest revealed subunit of IL-17R complex is IL-17RA; soon after, other subunits of this complex have been recognized and termed as IL-17RB, IL-17RC, IL-17RD, and IL-17RE [34, 35]. Activation of

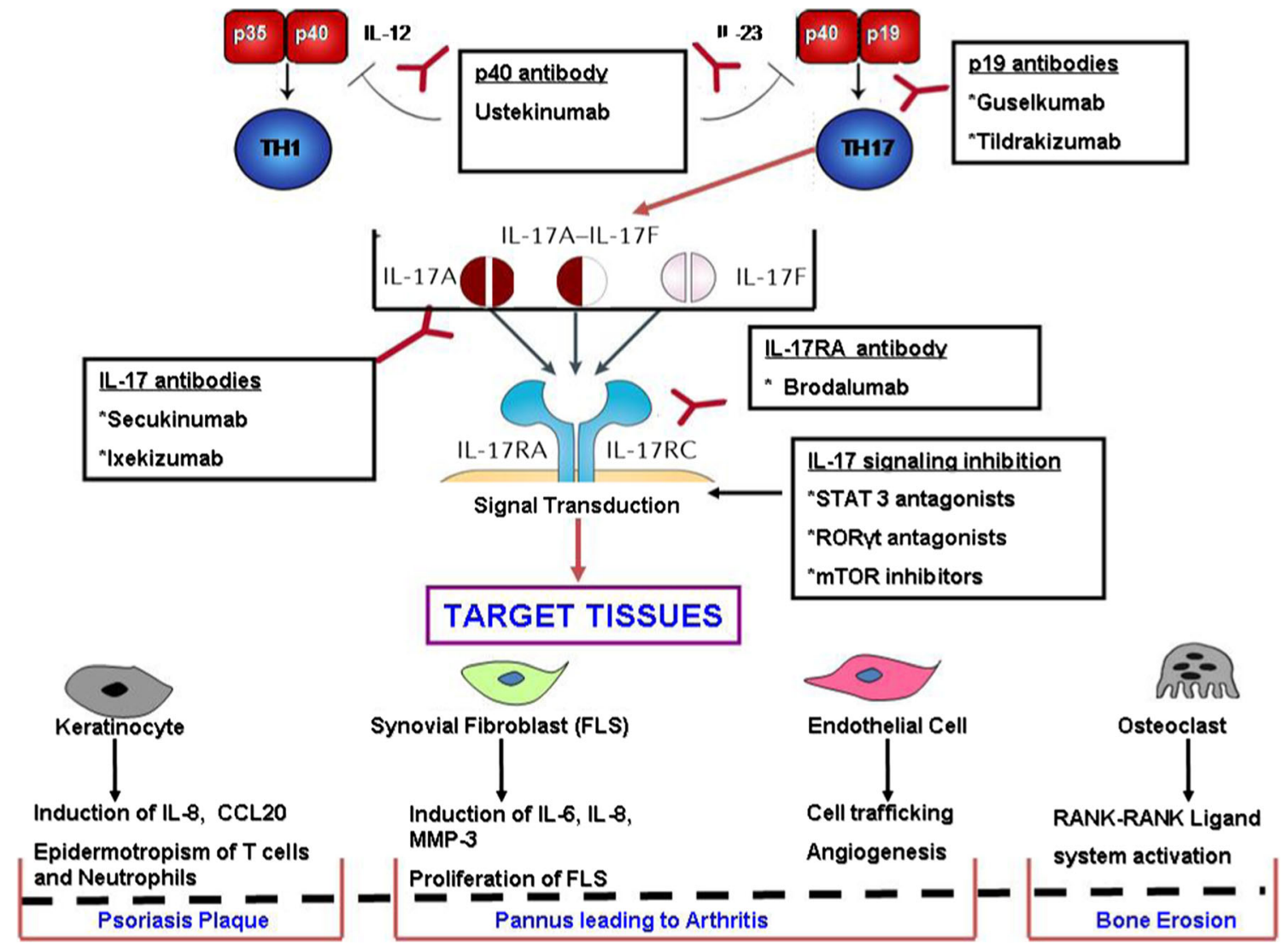

Fig. 1. IL-23/IL-17 signaling cascade in the pathogenesis psoriatic disease and the mechanism of actions of the various pharmacological drugs for psoriasis/psoriatic arthritis acting through this signaling system. 
intracellular signaling occurs through the binding of IL-17A and IL-17F to the receptor complex formed by IL-17RA and IL-17RC [35, 36]. Moreover, IL-17A also signals through a receptor complex of IL-17RA and IL-17RD [37]. Therefore, in the formation of functional IL-17R complex, IL-17RA is playing the pivotal role and might be a broad and thus a more potent therapeutic target compared to other ligands of IL-17 family.

\section{IL-17 in psoriatic disease}

Studies of human psoriatic lesions support a role for IL-12 and IL-23 in psoriasis. Several human studies have demonstrated increased levels of IL12p40 (shared by IL-12 and IL-23) messenger RNA (mRNA) in psoriatic lesions; further studies have demonstrated enrichment of psoriasis plaques with IL-23 specific p19 subunit [38-41]. Multiple studies have demonstrated increased expression of IL-17A and IL-17F in psoriatic skin in contrast to the nonlesional psoriatic skin, and the upregulation of IL-17A illustrated positive association with disease severity $[42,43]$. Moreover, there is increased expression of the $T_{h} 17$ specific transcription factor (ROR $\gamma t$ ) and $T_{h} 17$ inducing cytokines (IL-23, IL-6, IL-1 $\beta$ ) in lesional psoriatic skin vs. nonlesional skin and skin of healthy volunteers [44]. Evidences also show overexpression of $\mathrm{T}_{\mathrm{h}} 17$ specific CC chemokine receptor, CCR6 and its ligand CCL20 in psoriatic skin lesions, and induction of CCL20 from keratinocytes by IL-17 [45]. All of these reports reflect the pivotal role of IL-17 in psoriasis. The major pathological roles of IL-17 in psoriasis are as follows: recruiting neutrophils to the epidermis of psoriatic lesion by increasing neutrophil-specific chemokines [46, 47]; employing additional pathogenic $\mathrm{T}_{\mathrm{h}} 17$ cells by regulating CCL20 release from keratinocytes $[45,46]$; stimulating expression of significant antimicrobial peptides of psoriasis like $\beta$-defensin, S100A7, S100A8, and S100A9, which consecutively act as pro-inflammatory stimulus $[46,48]$; it also disrupts the skin barrier by downregulating expression of filaggrin and adhesion molecules in keratinocytes [49] and induces TNF- $\alpha$ release from dendritic cells and macrophages $[28,46]$.

Results of our study suggest that synovium of psoriatic arthritis is enriched with IL-17 producing CD4+ effector memory T cells and functionally active IL17RA, the most well-recognized receptor for IL-17 [50••]. Several reports suggest that IL-17 can influence bone and cartilage destruction in inflammatory arthritis [51, 52]. In animal arthritis model, disease severity is less in IL-17deficient mice [53]. IL-17 receptor deficiency results in impaired synovial expression of IL-1, MMP-3, MMP-9, and MMP-13 and prevents cartilage destruction during chronic reactivated streptococcal cell wall-induced arthritis [54]. To understand the role of IL-17 in the joint pathology of PsA, we examined the ability of IL-17 to induce MMP-3 and cytokines by FLS obtained from PsA synovium and have observed that FLS in PsA are tuned to a robust response with IL-17. There was a marked upregulation of IL-6, IL-8, and MMP-3 upon exposure to IL-17 in cultured FLS from PsA patients [50••]. IL-17 also promotes bone erosion through the upregulation of RANKL $[55,56]$ a key regulator of osteoclast neogenesis. Thus, the downstream effects of IL-17 are likely to influence all the major components of the pathologic events in skin and joint tissues of psoriatic disease. 
Ustekinumab is an anti-IL-12/23 monoclonal antibody that binds to the common p40 subunit of IL-12 and IL-23, thus has the potential to inhibit the proinflammatory cytokines from $\mathrm{T}_{\mathrm{h}} 1$ and $\mathrm{T}_{\mathrm{h}} 17$ cells. Ustekinumab is approved by the FDA for the treatment of psoriasis and PsA.

Ustekinumab has been reported to be therapeutically effective in psoriasis in two phase 3 trials, and further, it has been found to be superior to etanercept $[57,58]$. With regard to PsA, a randomized, double-blind, placebo-controlled crossover trial of ustekinumab in PsA showed improvement in the American College of Rheumatology (ACR) response rates and significant improvement in skin disease, enthesitis, dactylitis, and physical functioning but required a higher dose than that used for treating psoriasis [59]. Analogous results were again reported with ustekinumab in a randomized, placebo-controlled, phase III clinical trial in PsA patients who had received anti-TNF and DMARD treatment [60 $]$. PSUMMIT 1 was a randomized control trial $(n=615)$ where PsA patients received either ustekinumab $45 \mathrm{mg} /$ ustekinumab $90 \mathrm{mg}$ or placebo at weeks 0 and 4 and then every 12 weeks. At week 24, ACR20 responses were achieved by $42.4,49.5$, and $22.8 \%$ of patients, respectively [60•]. Improvements were also seen in dactylitis, enthesitis, and HAQ [61]. A similar ACR20 response for ustekinumab was seen in the PSUMMIT 2 trial in 312 patients with PsA [62].

Anti-IL-17 agents

IL-17 is a pro-inflammatory cytokine that has a crucial role in the pathogenesis of psoriasis and PsA. Till date, it has been the object of immense drug development research, and numerous biologic agents targeting this molecule are being explored in clinical studies of psoriasis and PsA. Following IL-17 and its receptor, targeted agents are going through phase II and phase III clinical trial for psoriatic disease:

(i) Secukinumab, a fully human IL-17A monoclonal antibody

(ii) Brodalumab, a fully human IL-17 receptor (IL-17RA) monoclonal antibody

(iii) Ixekizumab, a humanized anti-IL-17A monoclonal antibody

\section{Secukinumab}

Secukinumab is a human monoclonal IgG1k antibody that targets IL-17A. Several drug trial studies have repotted marked improvement of plaque psoriasis following treatment with subcutaneous injection of secukinumab. In a recent phase 3, randomized, double-blind, placebocontrolled 52-week trial (Efficacy of Response and Safety of Two Fixed Secukinumab Regimens in Psoriasis (ERASURE)), subcutaneous secukinumab was administered at a dose of $300 \mathrm{mg}$ or $150 \mathrm{mg}$ (administered once weekly for 5 weeks, then every 4 weeks). In this study, at week 12, the Psoriasis Area Severity Index (PASI) 75 rates were $81.6 \%$ 
with $300 \mathrm{mg}$ of secukinumab, $71.6 \%$ with $150 \mathrm{mg}$ of secukinumab, and $4.5 \%$ with the placebo $[63 \bullet]$.

Currently, phase III trials of secukinumab for psoriasis and PsA are going on. At the American College of Rheumatology (ACR) (Boston, 2014), the results of two phase 3 trials in PsA were reported [64, 65]. In the FUTURE 1 randomized placebo-controlled study $(n=606)$, patients received secukinumab intravenous loading dose of $10 \mathrm{mg} / \mathrm{kg}$ at baseline, weeks 2 and 4 , and then either 150 or $75 \mathrm{mg}$ every 4 weeks from week 8 . At 24 weeks, the ACR20 responses in $150 \mathrm{mg}$ dose arm, $75 \mathrm{mg}$ dose arm, and in the placebo group were 50.0, 50.5, and 17.3, respectively. Higher responses were seen in subjects naive to anti-TNF therapy. In the FUTURE 2 $(n=397)$ study [66], patients received subcutaneous secukinumab $300 \mathrm{mg}$, $150 \mathrm{mg}, 75 \mathrm{mg}$, and placebo at weeks 1, 2, 3, 4, and every 4 weeks thereafter. In this study, statistically significant improvement was noticed in ACR20 response, enthesitis, dactylitis, skin, function, and quality of life measures. At week 24, ACR20 responses were significantly greater with secukinumab: 54.0, 51.0, and $29.3 \%$ vs. $15.3 \%$, with secukinumab 300, 150 , and $75 \mathrm{mg}$ vs. PBO, respectively. In both the studies, serious adverse events were few and comparable with the placebo groups during the 16week study period.

\section{Brodalumab}

\section{Ixekizumab}

Brodalumab is a humanized monoclonal antibody that binds with high affinity to human IL-17 receptor (IL-17RA) and blocks the biologic activity of IL-17. A phase II study of brodalumab administered subcutaneously established its efficacy in patients with moderate to severe plaque psoriasis [67]. In this study, like in secukinumab, the PASI response on week 12 was also $\sim 80 \%$. This study encouraged to investigate the efficacy of brodalumab in PsA. In a phase II RCT, 168 PsA patients were randomized to brodalumab (140 or $280 \mathrm{mg}$ ) or placebo for 12 weeks. Participants in this study received brodalumab (140 or $280 \mathrm{mg}$ subcutaneously) or placebo on day 1 and at weeks $1,2,4,6,8$, and $10[68 \bullet \bullet]$. At week 12, the ACR20 responses in brodalumab $140 \mathrm{mg}$, brodalumab $280 \mathrm{mg}$, and placebo arms were 37, 39, and $18 \%$, respectively. Additional improvements in ACR20 and other measures (ACR50/70, DAS 28, HAQ-DI, dactylitis, and skin scores) were demonstrated at week 24 of the open-label extension. In patients with 140 and $280 \mathrm{mg}$ arms at 24 weeks, ACR20 responses were observed in 51 and $64 \%$, respectively. The effects were similar in patients who received anti-TNF as well as those who did not. Currently, phase III trials for brodalumab in patients with psoriasis are undergoing.

Ixekizumab is a fully human anti-IL-17A monoclonal antibody, which is injected subcutaneously. Results of one phase II study demonstrated that ixekizumab improved clinical symptoms in patients with moderate to severe 
psoriasis [69]. Phase III studies of ixekizumab in psoriasis and PsA are under way.

\section{0ther IL-23/IL-17 antagonists for psoriatic disease}

Two IL-23 inhibitors targeting the p19 subunit of IL-23 have been prepared and currently going through clinical trials to evaluate their therapeutic efficacy in psoriasis-guselkumab is a human monoclonal antibody $(\mathrm{mAb})$ directed against the p19 subunit of IL-23 [70].

Tildrakizumab is a humanized mAb targeting the p19 subunit of IL-23 [71].

Apart from developing new biologics targeting the surface molecules of $\mathrm{T}_{\mathrm{h}} 17$ cells or IL-17, an alternative approach is to target the signaling pathways associated with the $T_{h} 17$ cells. We have shown that IL-17 and IL-22 exert their mitogenic effect on keratinocytes (key effector cells in psoriasis) and synovial fibroblasts (key effector cells in psoriatic arthritis) through PI3K/Akt/mTOR cascade which suggests the therapeutic potential for development of small organic molecules by targeting these key mTOR kinases [72, 73].

\section{Potential risks of blocking the IL-23/IL-17 cytokine system}

$\mathrm{T}_{\mathrm{h}} 17$ cells play a critical role in both innate and acquired immune responses and thus important for host defense. In human genetics, defect in IL-17RA or IL17F makes prone to chronic mucocutaneous candidiasis; patients with this condition develop recurrent or persistent skin, nail, and mucosal infections caused by Candida albicans and to a lesser extent by Staphylococcus aureus [74]. So, theoretically, patients treated with IL-23/IL-17 antagonists may have increased risks for chronic mucocutaneous candidal infections and other infections.

Currently, extensive clinical research including multiple clinical trials is going on; a careful evaluation of these studies will be helpful to identify whether specific serious infection or any other major safety concern including cardiovascular risks are associated with these group of medications. Like in other biologics, IL-17A antagonists discussed here had also certain adverse events. The most commonly reported adverse events were nasopharyngitis, upper respiratory tract infection, arthralgia, and erythema at the injection site [67, 68••]. Rare episodes of neutropenia and leukopenia have been observed during treatment with anti-interleukin-17 biologic therapies [67, 68・•, 75].

\section{Conclusion}

Compared to RA, patients with psoriatic arthritis who fail anti-TNF agents or where anti-TNF is contraindicated do not have much treatment options. Here we have reviewed the significance of IL-23/IL-17 cytokine network in the pathogenesis of PsA and the novel drugs formulated for treatment of psoriatic disease by targeting this pathway. Ustekinumab is already FDA approved for PsA, and it is expected that the other preparations targeted against the IL-23/IL- 
17 cytokine system will be soon available for treatment of PsA and other autoimmune diseases.

\section{Compliance with Ethics Guidelines}

\section{Conflict of Interest}

Smriti K. Raychaudhuri and Siba P. Raychaudhuri declare that they have no conflict of interest.

\section{Human and Animal Rights and Informed Consent}

This article does not contain any studies with human or animal subjects performed by any of the authors.

\section{References and Recommended Reading}

Papers of particular interest, published recently, have been

highlighted as:

- Of importance

$\bullet \quad$ Of major importance

1. Raychaudhuri SP. A cutting edge overview: psoriatic disease. Clin Rev Allergy Immunol. 2013;44(2):10913.

2. Lowes MA, Bowcock AM, Krueger JG. Pathogenesis and therapy of psoriasis. Nature. 2007;445(7130):866-73.

3. Raychaudhuri SP, Farber EM. The prevalence of psoriasis in the world. J Eur Acad Dermatol Venereol. 2001;15(1):16-7.

4. Liu Y, Krueger JG, Bowcock AM. Psoriasis: genetic associations and immune system changes. Genes Immun. 2007;8(1):1-12.

5. Gladman DD, Farwell VT, Pellett F, Schentag C, Raham $P$. HLA is a candidate region for psoriatic arthritis evidence for excessive HLA sharing in sibling pairs. Hum Immunol. 2003;64(9):887-9.

6. Amherd-Hoekstra A, Naher H, Lorenz HM, Enk AH. Psoriatic arthritis: a review. J Dtsch Dermatol Ges. 2010;8(5):332-9.

7. Griffiths CE, Barker JN. Pathogenesis and clinical features of psoriasis. Lancet. 2007;370(9583):263-71.

8. Neimann AL, Shin DB, Wang X, Margolis DJ, Troxel AB, Gelfand JM. Prevalence of cardiovascular risk factors in patients with psoriasis. J Am Acad Dermatol. 2006;55(5):829-35.

9. Cohen AD, Sherf M, Vidavsky L, Vardy DA, Shapiro J, Mayerovitch J. Association between psoriasis and the metabolic syndrome. A cross-sectional study. Dermatology. 2008;216(2):152-5.

10. Gisondi P, Targher F, Zoppini F, Girolomoni G. Non-alcoholic fatty liver disease in patients with chronic plaque psoriasis. J Hepatol. 2009;51(4):75864.

11. Prey S, Paul C, Bronsard V, Puznenat E, Gourraud PA, Aractingi $\mathrm{S}$, et al. Cardiovascular risk factors in patients with plaque psoriasis: a systematic review of epidemiological studies. J Eur Acad Dermatol Venereol. 2010;24 Suppl 2:23-30.

12. Armstrong AW, Harskamp CT, Armstrong EJ. Psoriasis and metabolic syndrome: a systematic review and meta-analysis of observational studies. J Am Acad Dermatol. 2013;68(4):654-62.

13. Kurd SK, Troxel AB, Crits-Christoph P, Gelfand JM. The risk of depression, anxiety, and suicidality in patients with psoriasis: a population-based cohort study. Arch Dermatol. 2010;146(8):891-5.

14. Rahman P, Elder JT. Genetic epidemiology of psoriasis and psoriatic arthritis. Ann Rheum Dis. 2005;64 Suppl 2:ii37-9. discussion ii40-1.

15. Elder JT, Bruce AT, Gudjonsson JE, Johnston A, Stuart PE, Tejasvi T, et al. Molecular dissection of psoriasis: integrating genetics and biology. J Investig Dermatol. 2010;130(5):1213-26.

16. Chandran V, Raychaudhuri SP. Geoepidemiology and environmental factors of psoriasis and psoriatic arthritis. J Autoimmun. 2010;34(3):J314-21.

17. Bowes J, Orozco G, Flynn E, Ho P, Brier R, MarzoOrtega H, et al. Confirmation of TNIP1 and IL23A as susceptibility loci for psoriatic arthritis. Ann Rheum Dis. 2011;70:1641-4.

18. Filer C, Ho P, Smith RL, Griffiths C, Young HS, Worthington $\mathrm{J}$, et al. Investigation of association of the IL12B and IL23R genes with psoriatic arthritis. Arthritis Rheum. 2012;64(4):1302.

19. Huffmeier U, Uebe S, Ekici AB, Bowes J, Giardina E, Korendowych E, et al. Common variants at TRAF3IP2 are associated with susceptibility to psoriatic arthritis and psoriasis. Nat Genet. 2010;42:996-9. 
20. Raychaudhuri SP, Raychaudhuri SK. Role of NGF and neurogenic inflammation in the pathogenesis of psoriasis. Prog Brain Res. 2004;146:433-7.

21. Raychaudhuri SP, Raychaudhuri SK, Atkuri KR, Herzenberg LA, Herzenberg LA. Nerve growth factor: A key local regulator in the pathogenesis of inflammatory arthritis. Arthritis Rheum. 2011;63:3243-52.

22. Gottlieb AB, Lebwohl M, Shurun S, Sherr A, Gilleaudeau P, Singer G, et al. Anti-CD4 monoclonal antibody treatment of moderate to severe psoriasis vulgaris: results of a pilot, multicenter, multiple-dose, placebo-controlled study. J Am Acad Dermatol. 2000;43(4):595-604.

23. Wrone-Smith T, Nickoloff BJ. Dermal injection of immunocytes induces psoriasis. J Clin Invest. 1996;98(8):1878-87.

24. Raychaudhuri SP, Kundu-Raychaudhuri S, Tamura K, Masunaga T, Kubo K, Hanaoka K, et al. FR255734, a humanized, Fc-Silent, Anti-CD28 antibody, improves psoriasis in the SCID mouse-psoriasis xenograft model. J Investig Dermatol. 2008;128(8):1969-76.

25. Mitra A, Raychaudhuri SK, Raychaudhuri SP. Functional role of IL-22 in psoriatic arthritis. Arthritis Res Ther. 2012;14(2):R65.

26. Sherlock JP, Joyce-Shaikh B, Turner SP, et al. IL-23 induces spondyloarthropathy by acting on RORgammatp CD3pCD4-CD8- entheseal resident T cells. Nat Med. 2012;18:1069-76.

27. Raychaudhuri SP. Role of IL-17 in psoriasis and psoriatic arthritis. Clin Rev Allergy Immunol. 2013;44:183-93.

28. Lowes MA, Russell CB, Martin DA, Towne JE, Krueger JG. The IL-23/T17 pathogenic axis in psoriasis is amplified by keratinocyte responses. Trends Immunol. 2013;34(4):174-81.

29. Yao Z, Painter SL, Fanslow WC, Ulrich D, Macduff BM, Spriggs MK, et al. Human IL-17: a novel cytokine derived from T cells. J Immunol. 1995;155(12):5483-6.

30. Tesmer LA, Lundy SK, Sarkar S, Fox DA. Th17 cells in human disease. Immunol Rev. 2008;223:87-113.

31. Kuestner RE, Taft DW, Haran A, Brandt CS, Brender T, Lum K, et al. Identification of the IL-17 receptor related molecule IL-17RC as the receptor for IL-17F. J

Immunol. 2007;179(8):5462-73.

32. Liang SC, Long AJ, Bennett F, Whitters MJ, Karim R, Collins $\mathrm{M}$, et al. An IL-17F/A heterodimer protein is produced by mouse Th17 cells and induces airway neutrophil recruitment. J Immunol.

2007;179(11):7791-9.

33. Hymowitz SG, Filvaroff EH, Jp Y, Lee J, Cai L, Risser P, et al. IL-17s adopt a cystine knot fold: structure and activity of a novel cytokine, IL-17F, and implications for receptor binding. EMBO J. 2001;20(19):5332-41.

34. Yao Z, Spriggs MK, Derry JM, Strockbine L, Park LS, Vanden Bos T, et al. Molecular characterization of the human interleukin (IL)-17 receptor. Cytokine. 1997;9(11):794-800.

35. Ely LK, Fischer S, Garcia KC. Structural basis of receptor sharing by interleukin 17 cytokines. Nat Immunol. 2009;10(12):1245-51.
36. Toy D, Kugler D, Wolfson M, Vanden Bos T, Gurgel J, Derry J, et al. Cutting edge: interleukin 17 signals through a heteromeric receptor complex. J Immunol. 2006;177(1):36-9.

37. Coimbra S, Figueriredo A, Castro E, Rocha-Pereira P, Santos-Silva A. The roles of cells and cytokines in the pathogenesis of psoriasis. Int J Dermatol. 2012;51(4):389-95. quiz 395-8.

38. Lee E, Trepicchio WL, Oestreicher JL, Pittman D, Wang $\mathrm{F}$, Chamian F, et al. Increased expression of interleukin 23 p19 and p40 in lesional skin of patients with psoriasis vulgaris. J Exp Med. 2004;199(1):125-30.

39. Piskin G, Sylva-Steenland RM, Bos JD, Teunissen MB. In vitro and in situ expression of IL-23 by keratinocytes in healthy skin and psoriasis lesions: enhanced expression in psoriatic skin. J Immunol. 2006;176(3):1908-15.

40. Bovenschen HJ, van de Kerkhof PC, van Erp PE, Woestenenk R, Joosten I, Koenen HJ. Foxp3+ regulatory $\mathrm{T}$ cells of psoriasis patients easily differentiate into IL-17A-producing cells and are found in lesional skin. J Investig Dermatol. 2011;131(9):1853-60.

41. Wilson NJ, Boniface K, Chan JR, McKenzie BS, Blumenschein WM, Mattson JD, et al. Development, cytokine profile and function of human interleukin 17 producing helper T cells. Nat Immunol. 2007;8(9):950-7.

42. Lowes MA, Kikuchi T, Fuentes-Duculan J, Cardinale I, Zaba LC, Haider AS, et al. Psoriasis vulgaris lesions contain discrete populations of Th1 and Th17 T cells. J Investig Dermatol. 2008;128(5):1207-11.

43. Johansen C, Usher PA, Kjellerup RB, Lundsgaard D, Iversen L, Kragballe K. Characterization of the interleukin-17 isoforms and receptors in lesional psoriatic skin. Br J Dermatol. 2009;160(2):319-24.

44. van der Fits L, Mourits S, Voerman JS, Kant M, Boon L, Laman JD, et al. Imiquimod-induced psoriasis-like skin inflammation in mice is mediated via the IL-23/IL-17 axis. J Immunol. 2009;182(9):5836-45.

45. Homey B, Dieu-Nosjean MC, Wiesenborn A, Massacrier C, Pin JJ, Oldham E, et al. Up-regulation of macrophage inflammatory protein-3 alpha/CCL20 and CC chemokine receptor 6 in psoriasis. J Immunol. 2000;164(12):6621-32.

46. Girolomoni G, Mrowietz U, Paul C. Psoriasis: rationale for targeting interleukin-17. Br J Dermatol. 2012;167(4):717-24.

47. Nograles KE, Zaba LC, Guttman-Yassky E, FuentesDuculan K, Suarex-Farinas M, Cardinale I, et al. Th17 cytokines interleukin (IL)-17 and IL-22 modulate distinct inflammatory and keratinocyte-response pathways. Br J Dermatol. 2008;159(5):1092-102.

48. Liang SC, Tan XY, Luxenberg DP, Karim R, DunussiJoannopoulos K, Collins M, et al. Interleukin (IL)-22 and IL-17 are coexpressed by Th17 cells and cooperatively enhance expression of antimicrobial peptides. J Exp Med. 2006;203(10):2271-9.

49. Gutowska-Owsiak D, Schaupp AL, Salimi M, Selvakumar TA, McPherson T, Taylor S, et al. IL-17 
downregulates filaggrin and affects keratinocyte expression of genes associated with cellular adhesion. Exp Dermatol. 2012;21(2):104-10.

$50 . \bullet$ Raychaudhuri SP, Raychaudhuri SK, Genovese MC. IL17 receptor and its functional significance in psoriatic arthritis. Mol Cell Biochem. 2012;359(1-2):419-29.

This article provides undisputed evidence of the regulatory of Th17 cells, IL-17 and IL-17RA in the pathogenesis of psoriatic arthritis.

51. Chabaud M, Lubberts E, Joosten L, van den Berg W, Miossec P. IL-17 derived from juxta-articular bone and synovium contributes to joint degradation in rheumatoid arthritis. Arthritis Res. 2001;3:168-77.

52. Koshy PJ, Henderson N, Logan C, Life PF, Cawston TE, Rowan AD. IL-17 induces cartilage collagen breakdown: novel synergistic effects in combination with proinflammatory cytokines. Ann Rheum Dis. 2002;61(8):704-13.

53. Nakae S, Nambu A, Sudo K, Iwakura Y. Suppression of immune induction of collagen-induced arthritis in IL17-deficient mice. J Immunol. 2003;171(11):6173-7.

54. Koenders MI, Kolls JK, Oppers-Walgreen B, van den Bersselaar L, Joosten LA, Schurr JR, et al. Interleukin-17 receptor deficiency results in impaired synovial expression of interleukin-1 and matrix metalloproteinases 3, 9 , and 13 and prevents cartilage destruction during chronic reactivated Streptococcal cell wall induced arthritis. Arthritis Rheum. 2005;52(10):3239-47.

55. Koenders MI, Lubberts E, Oppers-Walgreen B, van den Bersselaar L, Helsen MM, Di Padova FE, et al. Blocking of interleukin-17 during reactivation of experimental arthritis prevents joint inflammation and bone erosion by decreasing RANKL and interleukin-1. Am J Pathol. 2005;167(1):141-9.

56. Kotake S, Udagawa N, Takahashi N, Matsuzaki K, Itoh $\mathrm{K}$, Ishiyama S, et al. IL-17 in synovial fluids from patients with rheumatoid arthritis is a potent stimulator of osteoclastogenesis. J Clin Invest.

1999;103(9):1345-52.

57. Leonardi CL, Kimball AB, Papp KA, Yeilding N, Guzzo C, Wang Y, et al. Efficacy and safety of ustekinumab, a human interleukin-12/23 monoclonal antibody, in patients with psoriasis: 76-week results from a randomised, double-blind, placebo-controlled trial (PHOENIX 1). Lancet. 2008;371:1665-74.

58. Griffiths CE, Strober BE, van de Kerkhof P, Ho V, Fidelus-Gort R, Yeilding N, et al. Comparison of ustekinumab and etanercept for moderate-to-severe psoriasis. N Engl J Med. 2010;362:118-28.

59. Gottlieb A, Menter A, Mendelsohn A, Shen YK, Li S, Guzzo C, et al. Ustekinumab, a human interleukin 12/ 23 monoclonal antibody, for psoriatic arthritis: randomised, double-blind, placebo-controlled, crossover trial. Lancet. 2009;373:633-40.

60. McInnes IB, Kavanaugh A, Gottlieb AB, Puig L, Rahman P, Ritchlin C, et al. Efficacy and safety of ustekinumab in patients with active psoriatic arthritis: 1 year results of the phase 3, multicentre, double-blind, placebocontrolled PSUMMIT 1 trial. Lancet. 2013;382:780-9.
Phase 3, multicentre, double-blind, placebo-controlled study demonstrated the effect of ustekinumab in psoriatic arthritis.

61. McInnes IB, Kavanaugh A, Puig L, Gottlieb A, Puig L, Paham $\mathrm{P}$, et al. Efficacy and safety of ustekinumab in patients with active psoriatic arthritis: 2 year results from a phase 3, multicenter, double-blind, placebocontrolled study [abstract]. Arthritis Rheum. 2013;65(suppl):L10.

62. Ritchlin C, Rahman P, Kavanaugh A, McInnes IB, Puig L, Li S, et al. Efficacy and safety of the anti-IL-12/23 p40 monoclonal antibody, ustekinumab, in patients with active psoriatic arthritis despite conventional nonbiological and biological anti-tumour necrosis factor therapy: 6-month and 1-year results of the phase 3, multicentre, double-blind, placebo-controlled, randomised PSUMMIT 2 trial. Ann Rheum Dis. 2014;73(6):990-9.

63. Langley RG, Elewski BE, Lebwohl M, et al. Secukinumab in plaque psoriasis -results of two phase 3 trials. N Engl J Med. 2014;371:326-38.

Provides phase 3 data of a randomized, double blind, placebo control trial about the efficacy of secukinumab in psoriasis.

64. Mease P, McInnes I, Kirkham B, et al. Secukinumab, a human anti-interleukin-17A monoclonal antibody, improves active psoriatic arthritis and inhibits radiographic progression: efficacy and safety data from a phase 3 randomized, multicenter, double-blind, placebo-controlled study. Arthritis Rheum. 2014;66(Suppl):S423. Abstract 953.

65. van der Heijde D, Landewe R, Mease P, et al. Secukinumab, a monoclonal antibody to interleukin17A, provides significant and sustained inhibition of joint structural damage in active psoriatic arthritis regardless of prior TNF inhibitors or concomitant methotrexate: a phase 3 randomized, double-blind, placebo-controlled study. Arthritis Rheum. 2014;66(Suppl):S424. Abstract 954.

66. McInnes IB, Mease P, Kirkham B, et al. Secukinumab, a human anti-interleukin-17A monoclonal antibody, improves active psoriatic arthritis: 24-week efficacy and safety data from a phase 3 randomized, multicenter, double-blind, placebo-controlled study using subcutaneous dosing. Late breaking oral presentation at: ACR/ ARHP Annual Meeting, Boston, MA, USA, 2014. Presentation number L1.

67. Papp KA, Leonardi C, Menter A, Ortonne JP, Kreuger JG, Kricorian G, et al. Brodalumab, an anti-interleukin17 -receptor antibody for psoriasis. N Engl J Med. 2012;366(13):1181-9.

68.• Mease PJ, Genovese MC, Greenwalk MW, Ritchlin CT, Beaulier AD, Deodhar A, et al. Brodalumab, an antiIL17RA monoclonal antibody, in psoriatic arthritis. N Engl J Med. 2014;370(24):2295-306.

This article provides key evidence for efficacy of IL-17 antagonist in psoriatic arthritis.

69. Leonardi C, Matheson R, Zachariae C, Cameron G, Li J, Edson-Heredia E, et al. Anti-interleukin-17 monoclonal antibody ixekizumab in chronic plaque psoriasis. $\mathrm{N}$ Engl J Med. 2012;366(13):1190-9. 
70. Sofen H, Smith S, Matheson RT, Leonardi CL, Claderon C, Brodmerkel C, et al. Guselkumab (an IL-23-specific mAb) demonstrates clinical and molecular response in patients with moderate-tosevere psoriasis. J Allergy Clin Immunol. 2014;133(4):1032-40.

71. Tausend W, Downing C, Tyring S. Systematic review of interleukin-12, interleukin-17, and interleukin-23 pathway inhibitors for the treatment of moderate-tosevere chronic plaque psoriasis: ustekinumab, briakinumab, tildrakizumab, guselkumab, secukinumab, ixekizumab, and brodalumab. J Cutan Med Surg. 2014;18(3):156-69.

72. Saxena A, Raychaudhuri SK, Raychaudhuri SP. Interleukin-17-induced proliferation of fibroblast-like synovial cells is mTOR dependent. Arthritis Rheum. 2011;63(5):1465-6.

73. Mitra A, Raychaudhuri SK, Raychaudhuri SP. IL-22 induced cell proliferation is regulated by PI3K/Akt/ mTOR signaling cascade. Cytokine. 2012;60(1):38-42.

74. Puel A, Cypowyj S, Bustamante J, Wright JF, Lim HK, Migaud M, et al. Chronic mucocutaneous candidiasis in humans with inborn errors of interleukin-17 immunity. Science. 2011;332:65-8.

75. Genovese MC, Van den Bosch F, Roberson SA, Bojin S, Biagini IM, Ryan P, et al. LY2439821, a humanized anti-interleukin-17 monoclonal antibody, in the treatment of patients with rheumatoid arthritis: a phase I randomized, doubleblind, placebo-controlled, proofof-concept study. Arthritis Rheum. 2010;62:929-39. 